\title{
Conteúdos representacionais da violência doméstica contra a mulher entre
}

\section{discentes de enfermagem}

\author{
Camila Daiane Silva ${ }^{1}$, Vera Lúcia de Oliveira Gomes ${ }^{2}$, Adriana Dora da Fonseca $^{3}$, \\ Ceres Braga Arejano ${ }^{4}$, Giovana Calcagno Gomes ${ }^{5}$
}

\footnotetext{
${ }^{1}$ Enfermeira, Doutora em Enfermagem. Professora Adjunta da Universidade Federal do Rio Grande. Rio Grande, RS, Brasil. E-mail: camilad.silva@yahoo.com.br.

${ }^{2}$ Enfermeira, Doutora em Enfermagem. Professora Titular da Universidade Federal do Rio Grande. Rio Grande, RS, Brasil. E-mail: vlog1952@gmail.com.br.

${ }^{3}$ Enfermeira, Doutora em Enfermagem. Professora Associada da Universidade Federal do Rio Grande. Rio Grande, RS, Brasil. E-mail: adriana@vetorial.net.

${ }^{4}$ Enfermeira, Doutora em Enfermagem. Professora Titular da Universidade Federal do Rio Grande. Rio Grande, RS, Brasil. E-mail: arejanoceres@gmail.com.

${ }^{5}$ Enfermeira, Doutora em Enfermagem. Professora Adjunta da Universidade Federal do Rio Grande. Rio Grande, RS, Brasil. E-mail: giovanacalcagno@furg.br.
}

Recebido: 11/04/2016.

Aceito: 29/09/2016.

Publicado: 22/12/2016.

Como citar esse artigo:

Silva CD, Gomes VLO, Fonseca AD, Arejano CB, Gomes GC. Conteúdos representacionais da violência doméstica contra a mulher entre discentes de enfermagem. Rev. Eletr. Enf. [Internet]. 2016 [acesso em: ____18:e1202. Disponível em: http://dx.doi.org/10.5216/ree.v18.40689.

\section{RESUMO}

Objetivou-se analisar os conteúdos representacionais da violência doméstica contra mulher entre discentes de enfermagem. Pesquisa qualitativa, fundamentada na Teoria das Representações Sociais. Coletaram-se os dados, entre agosto e novembro/2014, por entrevistas semiestruturada, analisadas por software. Participaram 33 discentes, 16 das séries iniciais e 17 das finais. Identificou-se duas categorias: conteúdos representacionais adquiridos no período préuniversitário e universitário. As séries iniciais elencaram o ensino médio, casos ocorridos com familiares e colegas. Entre as séries finais, o conhecimento foi adquirido durante semanas acadêmicas, grupos de pesquisa, atividades práticas e estágios. O conhecimento do senso comum é constante, principalmente, entre as discentes das séries iniciais e o reificado, entre as das séries finais. As ações do futuro cotidiano profissional podem ser pautadas nas vivências pessoais, no conhecimento do senso comum, reificado e no saber prático gerado durante a graduação. Destaca-se o impacto na formação para prestar assistência a mulheres/pessoas em situação de violência.

Descritores: Violência Doméstica; Violência contra a Mulher; Estudantes de Enfermagem; Prática Profissional.

\section{INTRODUÇÃO}

Considerada um problema de saúde pública, a violência doméstica contra a mulher (VDCM) acomete mulheres independentemente da classe social, cor, religião, cultura ou escolaridade. Mundialmente, 35\% das mulheres sofreram violência em algum momento de suas vidas ${ }^{(1)}$. O Mapa da Violência evidenciou que o 
Brasil ocupa uma das primeiras posições no ranking internacional de feminicídios ${ }^{(2)}$. Sendo que nele, desde 2006, vigora a Lei no 11.340, conhecida como Maria da Penha, que visa coibir a violência doméstica e familiar contra a mulher ${ }^{(3)}$.

Esse país conta com o disque-denúncia, serviço gratuito ${ }^{(4)}$, originalmente conhecido como Ligue 180. Somente em 2014 registrou 52.957 denúncias de violência contra a mulher, das quais $51,68 \%$ referiam-se à violência física, $31,81 \%$, à psicológica, 9,68\%, à moral, 1,94\%, à patrimonial, $2,86 \%$, à sexual, $1,76 \%$, a cárcere privado e $0,26 \%$, ao tráfico ${ }^{(5)}$.

Frente a esses expressivos índices, é fundamental que os profissionais de saúde reconheçam as diversas formas de manifestação da VDCM. Muitas vezes tais profissionais constituem o primeiro contato após a agressão, devendo prestar-Ihes assistência integral e qualificada. No entanto, profissionais reconhecem a falta de qualificação e capacitação para atuar nas situações de violência, evidenciando o despreparo ${ }^{(6-7)}$. Além de lacunas como essas, crenças, mitos e representações podem constituir entraves para uma assistência de enfermagem integral à mulher/pessoa em situação de violência.

Nesse sentido, as universidades têm o dever social de formar profissionais capazes de atuar com responsabilidade e compromisso sobre os problemas e situações de saúde/doença prevalentes em nível nacional ${ }^{(8)}$. Assim, a graduação em enfermagem pode oportunizar espaços de problematização e vivências relacionadas à temática. Considerando que a representação social de indivíduos ou grupos reconstitui a realidade com a qual se confrontam e para a qual atribuem um significado específico ${ }^{(9)}$, optou-se por investigar: Quais os conteúdos representacionais da VDCM entre discentes das séries iniciais e finais de um curso de graduação em enfermagem? O estudo teve como objetivo analisar esses conteúdos.

\section{MÉTODO}

Estudo descritivo, qualitativo, recorte da Tese de Doutorado: "Representações sociais de discentes de enfermagem acerca da violência doméstica contra a mulher", apresentada na Universidade Federal do Rio Grande/RS. Acreditando-se que o conhecimento reificado, adquirido ao da graduação em enfermagem, pode influenciar na representação das estudantes acerca da VDCM modificando-a, convidou-se discentes das três séries iniciais e das três finais para participarem. Excluíram-se as que rejeitaram o convite ou faltaram as aulas no período da coleta.

Entre agosto e novembro de 2014, coletaram-se os dados aplicando um questionário referente às informações pessoais, sociais e acadêmicas. Procedeu-se às entrevistas individuais, agendadas previamente. Elaborou-se um roteiro com questões abertas referentes às vivências pré-universitárias com a temática em estudo, bem como sua abordagem ao longo das disciplinas teórico-práticas.

Contou-se com uma sala reservada na área acadêmica para a gravação das entrevistas, mediante autorização das informantes. A duração média foi de meia hora. Há um consenso entre os experts da TRS que 30 entrevistas é o quantitativo mínimo para se recuperar as representações em um grupo ${ }^{(10)}$.

O tratamento dos dados foi pelo software Análise Lexical por Contexto de um Conjunto de Segmentos 
de Texto. O corpus formado pelo total de entrevistas, dividiu-se em seis classes de acordo com a relação existente entre as formas reduzidas. A classe apresentada contém 17\% do corpus, que corresponde a 138 do total de 800 Unidades de Contexto Elementar (UCEs). Essas são formadas por aproximadamente três linhas de texto, variando de acordo com o tamanho do corpus e a pontuação ${ }^{(11)}$. As falas foram identificadas pela letra " $D$ " (discente) e o número da ordem das entrevistas. O projeto foi aprovado sob o Parecer no 109/2014.

\section{RESULTADOS}

Entre as 33 discentes, 16 eram das séries iniciais e 17, das finais. Quanto à faixa etária, 18 tinham entre 17 e 23 anos e 15 tinham a idade situada entre 24 a 50 anos. A variável "série" não está associada estatisticamente, no entanto das sete entrevistas relacionadas, cinco correspondem a discentes das séries finais. Esta constatação permite acreditar que o conhecimento reificado, construído ao longo da graduação em enfermagem, predomina nos conteúdos representacionais.

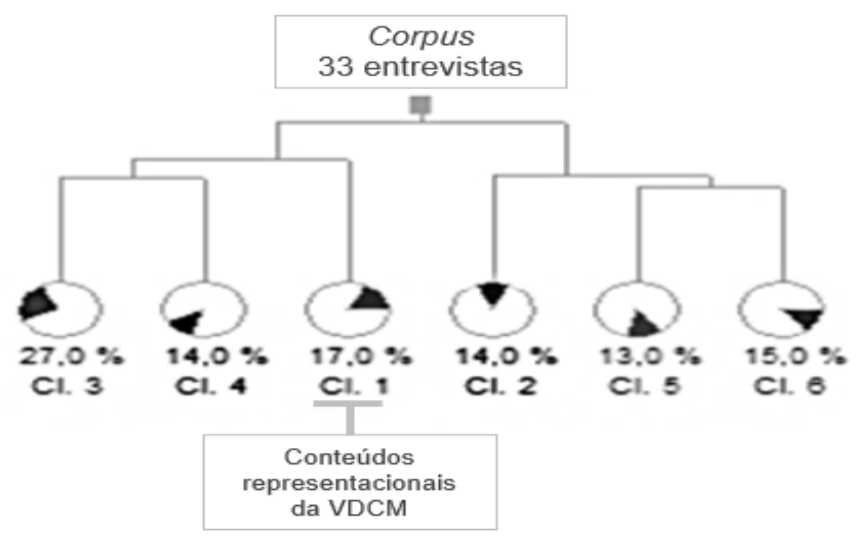

Figura 1: Classificação Hierárquica Descendente.

A classe possui 122 formas reduzidas principais com maior associação estatística à classe (Figura 2). Dentre as palavras com maiores valores de $\mathrm{khi}^{2}$ destacam-se: disciplina $\left(\mathrm{khi}^{2}=115\right)$; curso $\left(\mathrm{khi}^{2}=99\right)$; atividades_práticas $\left(\mathrm{khi}^{2}=95\right)$; particip $\left(\mathrm{khi}^{2}=90\right)$; evento $\left(\mathrm{khi}^{2}=87\right) ;$ abord $\left(\mathrm{khi}^{2}=86\right)$; disciplina_mulher $\left(\mathrm{khi}^{2}=81\right)$; lembr $\left(\mathrm{khi}^{2}=72\right)$; segundo_grau(ensino_médio) $\left(\mathrm{khi}^{2}=63\right) ;$ aula $\left(\mathrm{khi}^{2}=61\right) ; \operatorname{assunto}\left(\mathrm{khi}^{2}=60\right) ; \operatorname{tema}\left(\mathrm{khi}^{2}=58\right)$; disciplina_epidemio $\left(\mathrm{khi}^{2}=52\right) ; \quad \operatorname{seminário}\left(\mathrm{khi}^{2}=47\right) ; \quad$ grupo $\left(\mathrm{khi}^{2}=33\right) \quad$ coleg $\left(\mathrm{khi}^{2}=30\right) ; \quad$ palestra $\left(\mathrm{khi}^{2}=29\right)$; semana $\left(\mathrm{khi}^{2}=29\right)$; faculdade $\left(\mathrm{khi}^{2}=28\right)$. 


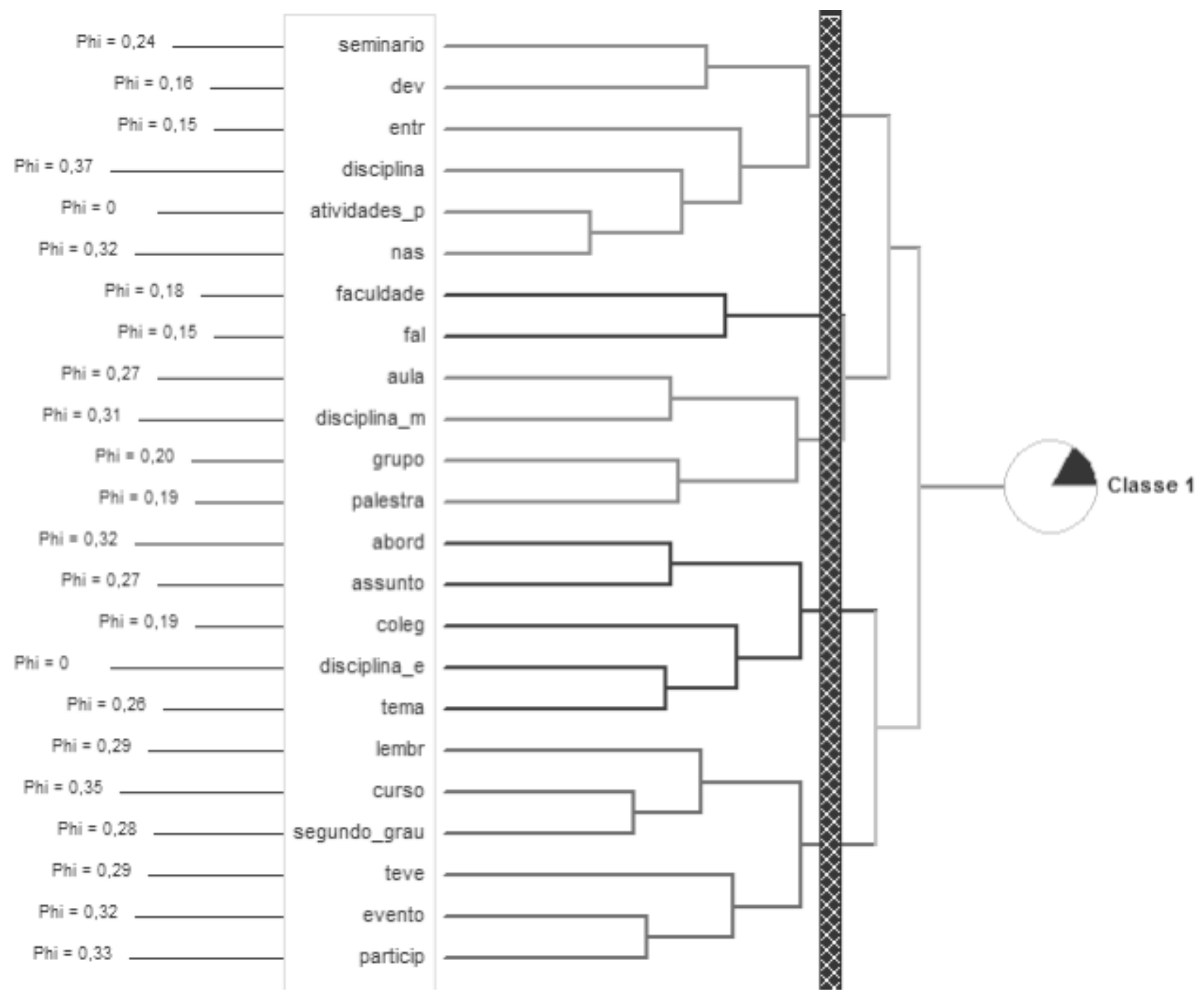

Figura 2: Dendrograma Hierárquico Ascendente.

Os conteúdos representacionais permeiam o contato das discentes com a temática da VDCM. As formas reduzidas evidenciam que tal contato ocorreu tanto no período pré-universitário, por meio de conversas com colegas, atividades durante o ensino médio, quanto no período universitário, sob forma de palestras, semanas acadêmicas, disciplinas, grupos de pesquisa e atividades práticas. Cada período foi apresentado em uma categoria.

\section{Conteúdos representacionais adquiridos no período pré-universitário}

As discentes representaram a VDCM como um assunto $\left(\mathrm{khi}^{2}=60\right)$ pertinente, mas difícil de ser abordado. Reconhecendo que requer maiores reflexões e aprendizado para a atuação profissional.

É realmente um assunto importante, a violência contra mulher está grande, são muitas nessa situação e ninguém está livre de pegar um paciente assim, vamos muitas vezes sem saber o que fazer por não ter sido passado mais informações. (D63)

A dimensão da temática da VDCM foi enfatizada pelas discentes. Tanto nas séries iniciais quanto finais, a mídia foi citada como a primeira fonte de informação sobre a violência e a lei protetiva. 
Desde a escola, em palestras, já fiz trabalhos sobre isso durante a escola, na mídia e em todo lugar. (D71) Jornal, quando fala de notícias. Aprendi bastante sobre Maria da Penha. Antes mesmo de entrar na faculdade já tinha conhecimento. (D92)

Outro contato com a temática foi por casos ocorridos no ambiente familiar com colegas $\left(\mathrm{khi}^{2}=30\right) \mathrm{e}$ conhecidos ou com as próprias discentes. Esses casos pautam o conhecimento do senso comum como verificado, principalmente, no depoimento das discentes das séries iniciais.

As primeiras vezes que ouvi foi quando ainda estava na escola, histórias de colegas, na família ou de vizinhos, dos meus colegas. (D67)

Na situação que vivencio no ambiente familiar[ ] a maior parte da minha infância foi difícil porque não conseguia sair de casa, tinha medo de não conseguir salvar minha mãe. (D23)

Sofro em casa a violência emocional. Do meu marido, não quer que estude, mas estou estudando. Impedida com chantagem, mas não cedo mais. (D24)

Minha colega[ ], acreditava que tinha provocado, pela questão da vítima se culpar. Por ciúmes, ele perdeu a cabeça e acabou cometendo agressão. Até que ponto os fatores culturais são envolvidos? (D10)

Durante o ensino médio $\left(\mathrm{khi}^{2}=63\right)$, a VDCM foi tema $\left(\mathrm{khi}^{2}=58\right)$, enfocado nas redações, panfletagens, campanhas e datas comemorativas. Violência foi um assunto $\left(\mathrm{khi}^{2}=60\right)$, abordado $\left(\mathrm{khi}^{2}=86\right)$ por profissionais da saúde e universitários. Reconheceram ser insuficiente o conhecimento adquirido no período préuniversitário, pois lembraram $\left(\mathrm{khi}^{2}=72\right)$ apenas vagamente do tema.

Trabalho de escola relacionado ao português, eram temas para fazer redação. (D71)

No oito de março falavam que era Dia da Mulher, vários temas relacionados, violência, câncer, mas muito pouco. (D63)

Teve uma campanha, uns universitários que distribuíam folhetos explicando. Era mais violência física, a imagem do panfleto era uma mulher com o olho roxo. Não lembro exatamente. (D126)

\section{Conteúdos representacionais adquiridos no período universitário}

As discentes distinguiram o conhecimento do senso comum do reificado. Nesse sentido, lembravam ter adquirido conhecimentos tanto por meio da mídia, quanto durante a faculdade $\left(\mathrm{khi}^{2}=28\right)$. As discentes das séries iniciais buscaram elencar, mesmo que superficialmente, o que aprenderam até o momento no curso de graduação.

Tudo que ouvi falar foi na mídia ou quando entrei na faculdade, na escola não. (D65)

Que eu lembro foi na faculdade[ ] não somente de mulheres, era violência em geral, idosos, crianças[ ], que tem mulheres que não sofrem somente a física, mas violência verbal, que dói mais ser xingada e humilhada, dependendo da situação, em público. (D124)

Por outro lado, as discentes das séries finais reconheceram a faculdade como o local para debater a temática, no entanto afirmaram ser insuficiente para a futura atuação profissional. Destaca-se que, apesar do sentimento de despreparo para atuar nas situações de VDCM e do papel social da faculdade na formação 
profissional, há necessidade de individualmente estudantes e profissionais assumirem a responsabilidade e se comprometerem com a própria capacitação para o enfrentamento do problema.

Precisamos muito mais preparo durante a faculdade. [ ]precisamos de mais eventos, mais disciplinas que tratem disso. Nas aulas tem tanta simulação realística, fazer uma sobre isso. Trazer didaticamente. (D36)

Não saímos totalmente preparadas para agir em situações meio inesperadas. Tem coisas que não tem como se preparar na faculdade. Se preparar para receber uma mulher que apanha do marido, não é uma coisa que se prepara. É uma coisa que vem desde sempre, o jeito que vai falar com a pessoa, como que vai abordar o assunto. É um processo de amadurecimento que temos que ter por conta, não depender da faculdade. (D92)

Buscando ir além do senso comum, algumas discentes lembraram de cursos ( $\left.k^{2}{ }^{2}=99\right)$ e eventos $\left(\mathrm{khi}^{2}=87\right)$ promovidos durante o curso. No entanto, relataram não ter participado por opção ou por incompatibilidade com o horário das atividades curriculares. Nesses casos, as discentes afirmaram ter interesse em participar de futuros eventos. Observa-se o reconhecimento de que há espaços para a construção do conhecimento reificado acerca da VDCM, porém eles nem sempre são aproveitados.

Algum evento, a semana acadêmica trouxe uma palestra, mas não participei. Soube que teve. (D78)

Ouvi falar de um evento que teve[ ] até fiquei interessada em participar só que estava na rede básica. (D132)

Teve um evento no início do ano, da prefeitura ou universidade. Só que não pude ver por causa da aula .(D65)

$\mathrm{O}$ conhecimento reificado acerca da VDCM foi construído a partir de seminários $\left(\mathrm{khi}^{2}=47\right)$ e palestras $\left(\mathrm{khi}^{2}=29\right)$ desenvolvidos na semana acadêmica $\left(\mathrm{khi}^{2}=29\right)$. Destaca-se a importância dos Grupos $\left(\mathrm{khi}^{2}=33\right)$ de Pesquisa, bem como a iniciativa do discente em se inserir neles, aproveitando as oportunidades de complementar o conhecimento reificado e transmiti-lo às clientes.

Para não dizer que nunca ouvi nada, no grupo pesquisa fizemos uma palestra pequena no grupo de gestantes e puérperas, na maternidade. Abordamos um pouco de violência contra mulher. (D39)

Algumas disciplinas $\left(\mathrm{khi}^{2}=115\right)$ foram elencadas pelas discentes por terem abordado a temática da VDCM, evidenciando a construção do conhecimento reificado. As das séries iniciais citaram a disciplina de epidemiologia $\left(\mathrm{khi}^{2}=52\right)$ que discutiu em aula $\left(\mathrm{khi}^{2}=61\right)$ de forma ampla. As que ainda não haviam cursado uma disciplina que tivesse abordado o tema demonstraram ter expectativas em relação ao desenvolvimento do curso, referindo-se principalmente à disciplina de saúde da mulher $\left(\mathrm{khi}^{2}=81\right)$.

Disciplina de epidemio trouxeram como assunto para discussão, não somente em mulheres, mas em idosos. (D124) Tenho a expectativa que tenha uma abordagem a mais sobre esse assunto, principalmente na disciplina de mulher e o que poderia fazer nesses casos para ficar mais preparada, porque com certeza vai aparecer durante nossa vida profissional. (D33)

Vou me preparar, espero aprender bastante na disciplina de mulher, criança, saúde do trabalhador. (D32)

Por outro lado, as estudantes das séries finais elencaram as disciplinas de saúde da criança e da mulher $\left(\mathrm{khi}^{2}=81\right)$, que abordaram a temática por meio de seminários $\left(\mathrm{khi}^{2}=47\right)$ ou trazendo convidados especiais. Algumas afirmaram lembrar vagamente a abordagem da violência, necessitando de uma problematização mais específica e profunda. 
Tivemos um seminário em criança, a respeito de adolescência e violência em geral, violência foi um dos itens abordado. Em mulher não lembro de ter tido uma abordagem específica. (D78)

Na disciplina da mulher. Foram convidados dois advogados que falaram bastante da Lei Maria da Penha, como que as mulheres devem procurar e fazer. Foi só essa palestra mesmo, não teve mais nenhuma aula falando. (D92)

As discentes elencaram o conhecimento reificado construído por meio das atividades práticas e estágios. As das séries iniciais realizaram visitas ao hospital, mas admitiram não lembrar se houve alguma situação relacionada à VDCM. Por outro lado, aquelas que se envolveram desde o início da graduação em atividades extraclasse e projetos disponibilizados pelo curso demonstraram maior sensibilidade para a temática, embora pouco instrumentalizadas para o atendimento.

Nas atividades práticas nunca vi, fiz quatro visitas técnicas no hospital, se vi não sabia que era violência contra mulher. Não foi passado para mim. (D126)

Nessas coletas de pesquisas teve uma situação que uma mulher não quis responder. Foi aquela coisa muito sucinta e ela estava cheia de hematomas. Não deixou entrar na casa nem falar com ninguém, foi na rua. Estava com o rosto cheio de hematomas. Não podemos julgar[ ]. Oferecemos auxílio, se precisasse de alguma coisa, mas como ela não quis nos responder nem as perguntas do projeto, seria muito difíil atingir com perguntas mais pessoais, se ela precisasse de algum suporte, deixamos telefone. (D128)

As discentes das séries finais referiram as atividades extracurriculares e os estágios das disciplinas como oportunidades de contato com situações de VDCM, possibilitando a construção do conhecimento reificado. Nesses espaços elas acompanharam os profissionais durante o atendimento, observando reações, ações e providências tomadas em relação à violência.

Nas atividades práticas chegou uma mulher com a cara toda deformada e o marido junto. [] Ele ficou esperando[ ], vi que os médicos não conseguiram esconder o choque, [ ]porque o marido prestou socorro. Participo da liga do trauma. Senti pena no pior sentido por ver que ela iria continuar passando por aquilo porque ele levou e depois foi embora com ela. (D132)

No estágio de mulher uma paciente, contou para o parceiro que estava grávida e ele tentou jogar ela do cais. [] Fomos orientadas a não fazer nada naquele momento porque ela poderia não seguir o pré-natal. Ficou combinado com a equipe que quando ela viesse novamente, iriam investigar essa história melhor. (D54)

A atenção básica é campo de atuação, principalmente durante os estágios curriculares. Esse espaço é fundamental para a construção profissional. As discentes relataram acompanhar a atuação da enfermeira, percebendo a importância do vínculo e confiança com as mulheres. Reconheceram a dificuldade principalmente com a emissão de opiniões e pré-julgamentos. Próximas da conclusão do curso e pautadas no conhecimento reificado, consideraram alguns pontos que deveriam ter sido aprofundados em disciplinas básicas.

Na rede básica atendemos com a enfermeira. [ ] Os pacientes confiam nas enfermeiras, tudo que falava, ela acolhia, dizia que iria fazer. Me senti confiante com a situação porque parece que foi resolvida naquele momento. 
[] Fiquei muito triste, dois sentimentos, tristeza e impotência, sem saber o que fazer, mas a enfermeira foi conduzindo[ ]. Encaminhamos para o NASF, fizemos visita com a agente para ver como está a situação. (D36) Quando a mulher chega, o laudo é no centro obstétrico, onde fiz meu estágio. Ninguém acreditava, mas ela foi estuprada pelo próprio marido. Não temos nenhuma preparação, porque a nossa disciplina de psicologia é muito falha, é ínfima[ ]. Não abordamos depressão pós-parto, como abordar um paciente violentado[ ]. Foi realizado o acolhimento, história prévia, exame físico, [ ] se pretendia voltar para casa, explicado que existe aquela casa abrigo que podem ficar e filhos também. Ninguém iria obrigar ela a denunciar ou julgar caso ela quisesse voltar para casa, a conduta achei bem correta. (D39)

Apesar da falha identificada na disciplina, foi possível suprir esse conhecimento durante a realização do estágio curricular. Momento propício para as discentes aprofundarem seus conhecimentos teóricos, sanar dúvidas e preencherem as lacunas ainda existentes.

\section{DISCUSSÃO}

Considera-se que as "representações sociais têm suas raízes nos conceitos elaborados pelos grupos humanos como produto das interações contínuas e das visões de mundo de seus membros"(10). Os conhecimentos do senso comum e reificado permeiam a construção da representação da VDCM. Nesse sentido, os conteúdos representacionais evidenciaram o contato das discentes com a temática, no ambiente pessoal, pré-universitário e durante a graduação.

As discentes das séries iniciais e finais reconheceram a importância e a dificuldade de abordar a VDCM, bem como a necessidade de maiores reflexões. A violência é um problema de saúde pública que acarreta severas consequências para as mulheres, nas esferas física, mental e reprodutiva ${ }^{(12)}$. Ainda, as discentes elencaram a mídia escrita e televisiva como fontes de informação. Em 2014, a mídia televisa contribuiu para que a Central de Atendimento à Mulher chegasse ao conhecimento das mulheres em situação de violência, responsabilizando-se por $47 \%$ da procura pelo serviço ${ }^{(5)}$.

Enfatiza-se que, para produzir representações, o fenômeno deve ter pertinência cultural e social, estar em todos os lugares a todo o momento, tanto no espaço coletivo quanto no individual ${ }^{(13)}$. Nesse sentido, principalmente as séries iniciais relataram o primeiro contato com o fenômeno por meio de casos ocorridos na vida pessoal, com amigos, colegas e familiares. As experiências pessoais com situações de violência podem ancorar a representação, influenciando na atuação profissional da futura enfermeira.

Uma pesquisa realizada com universitários japoneses, inclusive da saúde, identificou que a maioria ouviu falar sobre violência no namoro na mídia, palestras na escola/universidade, amigos ou familiares e seminário fora da escola/universidade ${ }^{(14)}$. Da mesma forma, amigos e familiares foram citados pelas discentes como fontes de informação.

Reforçando conhecimento do senso comum, algumas discentes relataram a ocorrência da violência no âmbito pessoal, como a proibição de estudar e as consequências para os filhos. Uma pesquisa realizada no Paquistão identificou que as mulheres em situação de violência revelaram que suas mães também foram 
espancadas pelos maridos, assim, é transmitido um comportamento tolerante ao longo de gerações em sociedades em que as disparidades de gênero estão culturalmente enraizadas ${ }^{(15)}$.

Evidenciando o conhecimento reificado da VDCM, as discentes reconheceram a abordagem durante graduação, por meio de seminários, palestras e semanas acadêmicas. No entanto, algumas priorizaram outras atividades acadêmicas no mesmo horário. Destaca-se a abordagem da temática em disciplinas como epidemiologia, saúde da criança e saúde da mulher. Essa também foi identificada em uma pesquisa realizada com estudantes do último ano de enfermagem de uma universidade localizada no Estado do Rio Grande do $\mathrm{Sul}^{(16)}$.

Estudo realizado com estudantes do Estágio Curricular Supervisionado identificou que o enfermeiro supervisor é visualizado como um modelo a ser seguido após a graduação. Por isso, o enfermeiro deve estar ciente de sua responsabilidade como referência para o graduando. Os autores destacaram que o estágio é uma oportunidade ímpar na formação do acadêmico, período em que poderá sofrer influências na identidade e perfil como futuro profissional ${ }^{(17)}$. Outra pesquisa realizada com estudantes de enfermagem identificou que a temática não deveria ser abordada apenas na disciplina da mulher, mas debatida durante todo o curso e com maior carga horária ${ }^{(16)}$.

O sentimento de despreparo para atuar em situações de VDCM é uma constante entre as discentes das séries finais. Estudo realizado com estudantes de universidades espanholas, em 2013, identificou que, apesar de se sentirem sensibilizados, os participantes não estavam preparados para atuar. Identificou também que as intervenções propostas pelos universitários se fundamentavam mais em conhecimento popular do que na formação específica ${ }^{(18)}$.

Próximas da conclusão do curso e pautadas no conhecimento reificado, as discentes avaliaram as disciplinas básicas como a de psicologia, apontando pontos fracos que deveriam ter sido aprofundados pela perspectiva da enfermagem. De maneira semelhante, uma pesquisa com estudantes do último ano de enfermagem, de uma universidade ao sul do país, em 2013, evidenciou que a temática violência deveria ser trabalhada desde o início da graduação, abordada de maneira contínua ao longo dos semestres, mas principalmente nos últimos, pela proximidade da conclusão(16).

Verificou-se que as discentes das séries finais enfatizaram suas responsabilidades e maturidade para aprofundar os conhecimentos e não apenas esperar pela faculdade. Maturidade também foi elencada em outro estudo com estudantes de enfermagem, como algo necessário para relacionar a teoria com prática no que tange à VDCM ${ }^{(16)}$.

Visualizam-se as disciplinas básicas e profissionalizantes como geradoras do conhecimento reificado, principalmente nos diversos campos de atuação das discentes. Cada discente poderá fundamentar suas ações do cotidiano profissional a partir de suas vivências pessoais, do conhecimento do senso comum e reificado, bem como do saber prático gerado durante a graduação. Acredita-se que o saber técnico profissional $^{(19)}$, uma nova forma de construção do conhecimento recentemente proposta na Teoria das Representações Sociais, e as representações podem contribuir para atuação das discentes em situações de 
VDCM.

\section{CONSIDERAÇÕES FINAIS}

Os conteúdos representacionais da VDCM permeiam o contato das discentes com a temática. Assim, o conhecimento do senso comum é constante na representação da VDCM. As das séries iniciais elencaram a mídia, palestras durante o ensino médio, casos ocorridos com elas ou com familiares e colegas como formadores de suas representações. As das séries finais evidenciaram que o conhecimento reificado adquirido ao longo do curso permeia suas representações. Assim, citaram as semanas acadêmicas, grupos de pesquisa, atividades e estágios curriculares. Destaca-se que as disciplinas de epidemiologia, saúde da criança e saúde da mulher foram elencadas como fontes de conhecimento.

Verifica-se que o estudo alcançou seu objetivo, no entanto, os resultados constituem uma primeira análise de um grupo específico. Para superar tais limitações, evidencia-se a necessidade de ampliar a outras áreas da saúde, em diferentes contextos e universidades. Dentre os possíveis impactos, destaca-se a formação de discentes para prestar assistência à mulheres/pessoas em situação de violência. Para tanto, buscou-se inicialmente espaço na disciplina de saúde da mulher para dialogar a temática com os discentes do curso de graduação em enfermagem, no qual se realizou esta pesquisa. A longo prazo, espera-se que a pesquisa possa alertar outras instituições de ensino superior, principalmente na área da enfermagem, bem como serviços de saúde, sensibilizando os responsáveis para a inclusão nos conteúdos programáticos, reuniões de equipe, problematizando questões éticas, políticas e legislativas.

\section{REFERÊNCIAS}

1. Who. Violencia contra la mujer, violencia de pareja y violencia sexual contra la mujer. 2014. [acesso 08 set 2016 ]. Available from: http://www.who.int/mediacentre/factsheets/fs239/es/.

2. Waiselfisz JJ. Mapa da Violência 2015 homicídio de mulheres no Brasil. Flacso Brasil, 2015.

3. Lei n. 11.340, de 7 de agosto de 2006. [Internet]. Dispõe sobre a Lei Maria da Penha. Diário Oficial da União. 2006. [acesso em: 07 set 2016]. Disponível em: http://www.planalto.gov.br/ccivil_03/_ato2004-2006/2006/lei/l11340.htm 4. Central de Atendimento a Mulher. Secretaria de Políticas para as mulheres. 2013. [acesso 08 set 2016]. Disponível em: http://www.spm.gov.br/ligue-180.

5. Balanço 2014 da Central de Atendimento à mulher. Secretaria de Políticas para as Mulheres Presidência da República. 2015.

6. Silva EB, Padoin SMM, Vianna LAC. Mulher em situação de violência: limites da assistência. Ciência \& Saúde Coletiva. 2015;20(1):249-58.

7. Nascimento EFGA, Ribeiro AP, Souza ER. Percepções e práticas de profissionais de saúde de Angola sobre a violência contra a mulher na relação conjugal. Cad. Saúde Pública. 2014;30(6):1-10.

8. Brasil. Diretrizes Curriculares Nacionais dos Cursos de Graduação em Enfermagem, Medicina e Nutrição. 2001. [acesso em 07 set 2016]. Disponível em: http://portal.mec.gov.br/dmdocuments/ces1133.pdf.

9. Silva LA, Gomes AMT, Oliveira DC, Souza MGG. [Social representations of aging in institutionalized psychiatric patients]. Esc Anna Nery. 2011;15(1):124-31.

10. Santos EI, Gomes AMT, Oliveira DC. Representations of vulnerability and empowerment of nurses in the context of HIV/AIDS. Texto contexto enferm. 2014; 23(2):408-16.

11. Camargo BV. Alceste: um programa informático de análise quantitativa de dados textuais. In: Moreira ASP. 
Perspectivas teórico-metodológicas em representações sociais. João Pessoa: UFPE Editora Universitária; 2005.

12. Taherkhani S, Negarandeh R, Simbar M, Ahmadi F. Iranian Women's experiences with intimate partner violence: a qualitative study. Health Promot Perspect. 2014; 4(2): 230-239. [acesso em 08 set 2016]. Disponível em:

http://www.ncbi.nlm.nih.gov/pubmed/25649136

13. Sá CP. A construção do objeto de pesquisa em representações sociais. Rio de Janeiro: UERJ, 1998. p. 45-59.

14. Ohnishi M, Nakao R, Shibayama S, Matsuyama Y, Oishi K, Miyahara H. Knowledge, experience, and potential risks of dating vilence among Japanese university students: a cross-sectional study. BMC Public Health. 2011;11:339. [acesso 06 set 2016]. Disponível em: http://www.ncbi.nlm.nih.gov/pmc/articles/PMC3111581/

15. Ali TS, Krantz G, Mogren I. Violence permeating daily life: a qualitative study investigating perspectives on Violence among women in Karachi, Pakistan. Int J Womens Health. 2012;4:577-85. [acesso 08 set 2016]. Disponível em: http://www.ncbi.nlm.nih.gov/pmc/articles/PMC3496530/

16. Rocha BD, LanderdahI MC, Cortes LF, Vieira LB, Padoin SMM. Violence against women: perceptions of nursing students about the focus on the formation. Investigación y Educación en Enfermería. 2015;33(2):206-68

17. Lima TC et al. Supervised curricular internship: analysis of the sutdent's experience. Rev Bras Enferm. 2014;67(1):133-40.

18. Rigol-Cuadra A, Galbany-Estragué P, Fuentes-Pumarola C, Burjales-Martí MD, Rodríguez-Martín D, BallesterFerrando D. Perception of nursing students about couples violence: knowledge, beliefs and professional role. Rev. Latino-Am. Enfermagem. 2015; 23(3):527-34.

19. Oliveira DC. A Teoria das Representações Sociais como grade de leitura da saúde e da doença: a constituição de campo interdisciplinar. In: Almeida AMO, Santos MFS, Trindade ZA. Teoria das representações sociais: 50 anos. Brasília, DF: Technopolitik, 2011. 